\title{
NEIBA
}

\section{Hidrocarbonetos têm lado? A Bolívia, o Globo e a Política Externa Brasileira}

EDUARDO DA NÓBREGA MONTEIRO

Vínculo Institucional: Mestrando do Programa de Pós-Graduação em Relações Internacionais da Universidade do Estado do Rio de Janeiro (PPGRI-UERJ), associado ao Laboratório de Mídia e Relação Internacionais (LEMRi-UFRJ), bolsista da Capes e bacharel em Relações Internacionais pelo IUPERJ. E-mail de contato é <eduardo.nobre.monteiro@gmail.com>

\section{Resumo:}

Em um contexto de forte polarização entre as forças progressistas e as forças tradicionais e conservadoras, a estatização do gasoduto bolivianobrasileiro - desdobramento de uma série de nacionalizações de hidrocarbonetos pelo governo Evo Morales -, em maio de 2006, não só ensejou acalorados debates com duras críticas sobre a resolução do conflito, mas também sobre a condução geral da política externa do governo de Luís Inácio Lula da Silva. Pouco estudado pelos cientistas sociais, segundo Aldé, Mendes e Figueiredo (2007), essa passagem importante do primeiro governo Lula da Silva remete a uma discussão mais ampla sobre a relação entre mídia e política. No Brasil, parte do debate sobre a crise da nacionalização do gasoduto boliviano-brasileiro ocorreu no Parlamento, parte em importantes órgãos da imprensa brasileira. Por isso, considerando as premissas do conceito de agenda setting e do método de valência, o objetivo deste artigo é analisar o comportamento da grande imprensa brasileira em relação a esse episódio, problematizando-o com o momento de reeleição do então presidente Lula da Silva, que perdeu $22 \%$ das intenções de votos dos eleitores com remuneração acima de 10 salários-mínimos, desde sua última eleição, em 2002, e contrastando-o com a posição oficial do governo brasileiro. Sem ceder às pressões da imprensa, o governo brasileiro manteve uma posição conciliadora em função de alguns cálculos políticos: a preservação da liderança brasileira no cenário regional e a importância geoestratégica dos recursos energéticos bolivianos para o Brasil. Selecionou-se o jornal O Globo, em formato impresso, considerando sua importância: na ocasião era o segundo jornal mais vendido no Brasil e um dos 10 membros do Grupo de Diários América, 


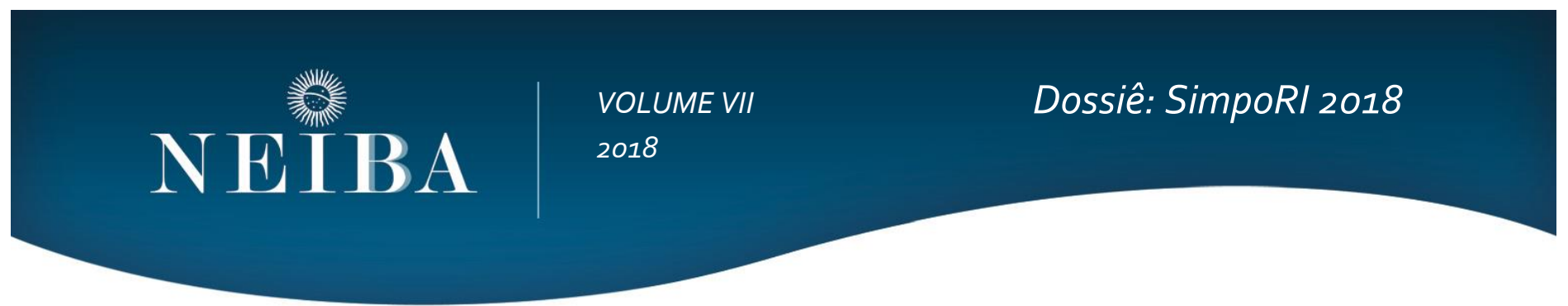

associação formada por jornais da América Latina com o fito de "informar e influir en la opinión pública en sus respectivos mercados". O marco cronológico definido observa que a cobertura do O Globo ficou mais negativa no mês de maio de 2006 para praticamente desaparecer após a reeleição do presidente Lula da Silva.

\section{Palavras-chaves:}

Bolívia; Brasil; O Globo; Política Externa; Nacionalização

\section{Abstract:}

In a context of strong polarization between progressive and conservative forces, the nationalization of the Bolivian-Brazilian gas pipeline -after several nationalizations of hydrocarbons by the Evo Morales administration - in May 2006, not only provoked heated debates with harsh criticism of the conflict's resolution, but also about the Brazilian foreign policy under the Luís Inácio Lula da Silva's administration. Social scientists have not considered as it deserves, according to Aldé, Mendes and Figueiredo (2007), this important moment from the first Lula da Silva's government, which inherently links to a broader discussion about the relationship between media and politics. In Brazil, part of the debate about the crisis of nationalization took place in the Parliament, and part at important organizations of the Brazilian press. Therefore, considering the concept of agenda setting and the valence method, this article analyzes the behavior of the mass Brazilian's press about this occasion. Taking into account the re-election's possibility of the president Lula da Silva, who lost $22 \%$ of voters' intentions of the upper class since his last election, in 2002, and in contrast to the official position of the Brazilian government. Without yielding to the press, the Brazilian government maintained a conciliatory position based on some political calculations: the preservation of the Brazilian leadership in the regional scenario and the geo-strategic importance of Bolivian energy resources for Brazil. The newspaper O Globo was selected, in print format, considering its importance: at the time it was the second best-selling newspaper in Brazil and one of the 10 members of the Diários América Group, an association formed by Latin American newspapers with the purpose of "informing and influence public opinion in their respective markets." The established chronological framework notes that O Globo's coverage became more negative in May 2006 to virtually disappear after the re-election of President Lula da Silva. 


\section{NEIBA}

VOLUME VII 2018
Dossiê: SimpoRI 2018

Keywords:

Bolivia; Brazil; O Globo; Foreign Policy; Nationalization 


\section{NEİBA}

\section{Introdução}

Para que se tenha um entendimento mais aprofundado do acontecimento, é necessário que haja uma contextualização espaço-temporal ${ }^{1}$ da Bolívia e do Brasil. Serão abordados os aspectos socioeconômicos do país andino e participação político-institucional dos grupos étnicos minoritários. Além disso, o contexto eleitoral será salientado como fundamental para as agitações sociais nos dois países. Em seguida, a nacionalização dos hidrocarbonetos bolivianos é demonstrada como sendo não só uma sucessão de protestos anteriores por participação política, mas também de promessas de campanha.

A Bolívia² não apresentava índices econômicos desprezíveis nos anos anteriores à nacionalização dos hidrocarbonetos. O país andino elevou seu PIB perto dos $4 \%$ durante quase toda a década de 1990, exceto em 1999, e manteve uma taxa de desemprego baixa até 2003. Ainda que tivesse apresentando um certo grau de desenvolvimento constante, o país apresentava, segundo Coutinho (2006), uma dívida social acentuada com os mais pobres e, em comparação aos demais países da região andina, a "Bolívia teve melhores indicadores de crescimento e emprego comparada aos outros países andinos nos anos 1990, mas endividou-se muito nesse período" (COUTINHO, 2006, p.807). Percebe-se que

\footnotetext{
1 De acordo com Dalle, Boniolo e Sautu (2005, p. 148), "las coordenadas espacio-tiempo deben aparecer siempre cuando explicitamos nuestro objetivo de investigación, lo que nos permite recortar el tema de investigación seleccionado".

Estou seguindo esta linha de raciocínio de Gerring (2007, p.19): "Note that the spatial boundaries of a case are often more apparent than its temporal boundaries. We know, more or less, where a country begins and ends, while we may have difficulty explaining when a country begins and ends. Yet some temporal boundaries must be assumed. This is particularly important when cases consist of discrete events - crises, revolutions, legislative acts, and so forth - within a single unit. Occasionally, the temporal boundaries of a case are more obvious than its spatial boundaries". Para um bom resumo, cf. Gerring (2011).

2 Para uma vasta investigação acerca da integração elétrica Brasil-Bolívia, cf. França (2015)
}

"[A] pobreza e a desigualdade são problemas mais antigos e que encontram raïzes estruturais na sociedade, tendo sofrido alterações variadas entre os países, nem todas elas necessariamente negativas. No entanto, por outro lado, a agenda de reformas liberalizantes tampouco chegou perto de alcançar os efeitos positivos inicialmente prometido" (COUTINHO, 2006, p. 813)

Dessa forma, o problema na Bolívia advém mais da questão política do que da mera questão econômica, como ficou sendo divulgado pela imprensa. No caso boliviano, as revoltas estão mais ligadas ao movimento indígena, que reclama mais participação social e material nas instituições políticas - Evo Morales era um entre os que estavam reivindicando mais participação. Evo Morales é eleito, em 2005, após a democracia

"[E]ntrar em crise na Bolivia já no fim dos anos 1990, depois do término do primeiro governo de Gonzalo Sanchez de Lozada (1994-1998). O ressentimento herdado da ditadura contra o novo presidente e ex-general Hugo Banzer (1998-2002), soma- do à crise econômica e ao auge da campanha de erradicação da coca (cultura tradicional na Bolivia), impulsionou grandes mobilizações sociais, das quais emergiu com vigor o Movimento ao Socialismo - MAS, do cocalero Evo Morales. A partir de então ocorreu uma seqüência de protestos mais intensos: a guerra das águas ${ }^{3}$, em 2000 (quando os movimentos sociais de Cochabamba conseguem impedir a privatização do serviço de distribuição); a guerra do gás que tomou conta do país em 2003, levando à deposição do presidente Sanchez de Lozada (no seu segundo mandato presidencial); e o conflito final, em 2005,

\footnotetext{
3 Para uma discussão geopolítica da guerra das águas e da nacionalização do
} gás, cf. Perreault (2006).

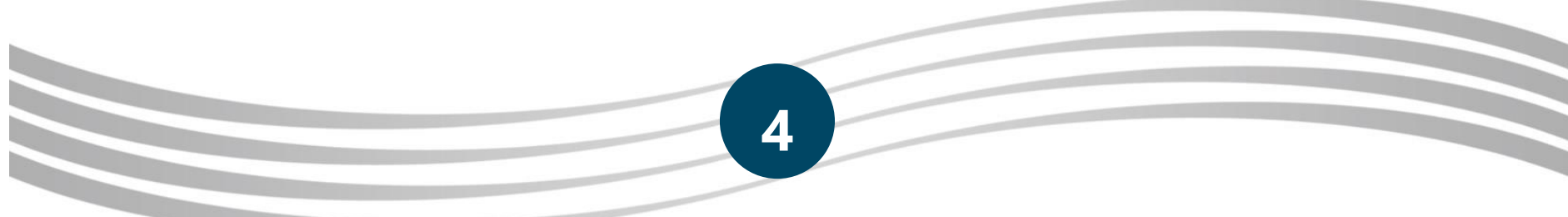




\section{NEIํA}

cuja renúncia de Carlos Mesa levou à ascensão de um governo provisório, tendo à frente Eduardo Rodrigues (juiz e então presidente da Corte Suprema)" (COUTINHO, 2006, p. 822)

No Brasil, as eleições de 2006 são essenciais para entender o processo doméstico, no qual a mídia se insere. Houve o Mensalão, os pedidos de impeachment, por parte da oposição ao Partido dos Trabalhadores (PT), e a nacionalização dos hidrocarbonetos bolivianos. Essa miríade de acontecimentos fez com que não só houvesse uma partidarização da imprensa, que se diz(ia) imparcial, mas também um declínio na confiança dos políticos, gerando uma espiral do cinismo4 (MIGUEL, 2008; ALDÉ, MENDES; FIGUEIREDO, 2007). Esse conceito ajuda a entender o motivo pelo qual se criou um certo cinismo com relação à política vis-à-vis a sociedade; tendo, nesse cenário, a mídia como criadora e reprodutora do pessimismo exacerbado que se evoluiu para um sentimento cínico. Levando em consideração que a mídia pode impor ou suprimir agendas, é imprescindivel que se leve em conta o movimento dos veículos de imprensa, que se utilizaram de acontecimentos nacionais e internacionais para criar atmosferas favoráveis ou não favoráveis.

No que se refere ao cenário eleitoral interno e à participação da imprensa, algumas considerações precisam ser feitas. Primeiramente, os candidatos em disputa eram Ana Maria Rangel (PRP), Cristovam Buarque (PDT), Geraldo Alckmin (PSDB), Heloísa Helena (PSOL), José Maria Eymael (PSDC), Luciano Bivar (PSL) e Luiz Inácio Lula da Silva (PT). É possível constatar, segundo Aldé, Mendes e Figueiredo (2007, p.161) duas tendências de eleições anteriores, que são tanto o fato da "mídia impressa nacional continua[r] dando

\footnotetext{
4 "Se os politicos se tornaram cínicos, isto se deu em reação ao cinismo dominante no público. O elemento central, porém, seria a mídia, responsável por difundir uma imagem negativa dos agentes da esfera pública" (MIGUEL, 2008, p. 254)
}

mais visibilidade aos candidatos à frente nas pesquisas" quanto o de dar "espaço maior, na imprensa, para os candidatos da situação". Com relação à política externa, Aldé, Mendes e Figueiredo (2007, p.162) estudam os jornais O Estado de São Paulo, Globo, o Jornal do Brasil e a Folha de São Paulo e constataram que o "grande pico de Lula Presidente entre 26 de abril e 9 de maio, por exemplo, ocorre em todos os jornais, e corresponde principalmente à crise da Bolivia, com leitura negativa nos jornais estudados".

Além dessas observações, é preciso salientar o motivo pelo qual se opta, neste artigo, a análise na imprensa e na política externa brasileira ${ }^{5}$. É importante que haja o ingresso de perguntas, metodologias e debates de outras áreas do saber na análise de política externa, que não seria tradicional nesse caso (RIGUEIRA, 2012). Segundo Pinheiro e Milani (2012, p.15, grifo meu), "os acontecimentos das últimas duas décadas do século $X X$ foram sem dúvida fundamentais para que houvesse um misto de resgate e renovação de teses da Análise de Política Externa na área de Relações Internacionais". Caso se pergunte o motivo pelo qual estuda-se a cobertura jornalística, Borba (2008, p. 310) sustenta que "[a] relevância de investigar a mídia decorre do fato de que, nas sociedades contemporâneas, a cobertura jornalistica funciona como uma das principais fontes de informação que os eleitores usam para escolha eleitoral".

O artigo se dividirá em três partes e uma conclusão. A primeira parte analisará a audiência pública no Senado Federal, em 2006, quando Celso Amorim debateu com senadores os acontecimentos na Bolívia. A segunda parte aplicará a metodologia de análise de valência no jornal o Globo, durante o mês de maio de 2006. A terceira parte será composta por três possibilidades de aplicação de teorias de política externa a partir das análises comunicacionais. A conclusão será para abordar os temas tratados e propor novos estudos.

\footnotetext{
5 Para uma aplicação na União Europeia, cf. Nitoiu (2015).
} 


\section{NEIBA}

\section{Senado Federal}

Análise da Audiência Pública de Celso Amorim ao

No dia og de maio de 2006, o Ministro das Relações Exteriores, Celso Amorim, vai até o Senado Federal para fazer parte de uma audiência pública sobre a situação entre o Brasil e a Bolívia. Nessa ocasião, senadores puderam questionar a formulação da política externa brasileira e puderam fazê-la, também, a partir de materiais da imprensa. Dessa forma, tanto o formulador de política externa quanto a imprensa acabaram por dialogar, no campo discursivo. A escolha dessa análise se dá pelo caráter mais neutro do local de discussão, uma vez que tanto as notas à imprensa do Itamaraty quanto às notícias e até entrevistas do Globo poderiam seguir critérios que pendessem para um dos lados. A audiência conta com 88 páginas e se encontra no site do Itamaraty.

O início da explanação de Celso Amorim é para destacar a importância das parcerias estratégicas com os países vizinhos ${ }^{6}$. Ele salienta que a integração sul-americana é, por exemplo, constitucional para se distanciar de quaisquer inferências de preferências pela região. Demonstra como o comércio evoluiu na região e como o Brasil se beneficiou "América Latina porque o conceito de Caribe está incluído no de América Latina, é hoje o nosso principal parceiro comercial, principal mercado para as exportações brasileiras" (BRASIL, 2006, p.3).

Boa parte de seu discurso diz respeito à linguagem diplomática, na qual realça os benefícios da própria integração regional e as boas relações com os vizinhos. Celso Amorim responde, subjetivamente, à imprensa que compreende a integração regional como comercial, ao ressaltar que "não quero defender que a integração tenha objetivos puramente comerciais, mas como muitos estão acostumados a ver as coisas por um ângulo mais mercantil, é

\footnotetext{
${ }^{6}$ Não se desloca muito do que seria uma linguagem diplomática, tal qual a que se encontra nos discursos diplomáticos. Para um resumo das relações entre Brasil e Bolívia, cf. Brasil (2018).
}

muito comum sobretudo nos artigos de imprensa" (BRASIL, 2006, p.3). Ainda que tenha ocorrido essa menção direta, o discurso transcorre de forma mais diplomática ao ressaltar que a aproximação regional advém desde o Presidente Sarney e que a:

"integração do Brasil na América do Sul e na América Latina - que é um objetivo constitucional -, como sempre tem sido todas as discussões que tenho mantido, com concordâncias e eventuais discordâncias, sobre os temas mais variados, como a ALCA, como a OMC, como aspectos do MERCOSUL" (BRASIL, 2006, p.1, grifo meu).

Nesse sentido, percebe-se que, a partir do momento em que os senadores começam as perguntas, o tema de imprensa aparece de forma mais frequente. São 14 aparições7, que têm maior foco com as perguntas do senador Arthur Virgílio (PSDB-AM), quem se faz valer dos argumentos da imprensa para os seus questionamentos. $O$ Ministro Celso Amorim responde, por sua vez, citando o jornal o $\mathrm{GLOBO}^{8}$, quando perguntado se o Brasil não deveria ter dito aos bolivianos que a nacionalização não seria positiva para eles. Além dele, o senador Jefferson Peres (PDT-AM) também cita a imprensa ao comentar o "peso desse assunto na imprensa" e, mais a frente, Celso Amorim rebate às

\footnotetext{
7 Nas páginas $3,19,25,28,47,50,50,53,54,54,64,68,68$ e 82 .

${ }^{8}$ Celso Amorim responde: "Senador, mencionou que nós devíamos ter dito para os bolivianos - acho que V.Exa. também mencionou isso - que nós devíamos ter dito para os bolivianos que é do interesse deles, que é dar um tiro no pé, não entregar o gás para o Brasil, que não há a possibilidade de inviabilizar o projeto, que não há a possibilidade de aumentar o preço de maneira, enfim, como está sendo colocado sem inviabilizar o projeto. Eu posso assegurar que tudo isso foi dito, foi dito para eles diretamente e foi dito publicamente por mim numa entrevista que está hoje no Globo" (BRASIL, 2006, grifo meu).
} 


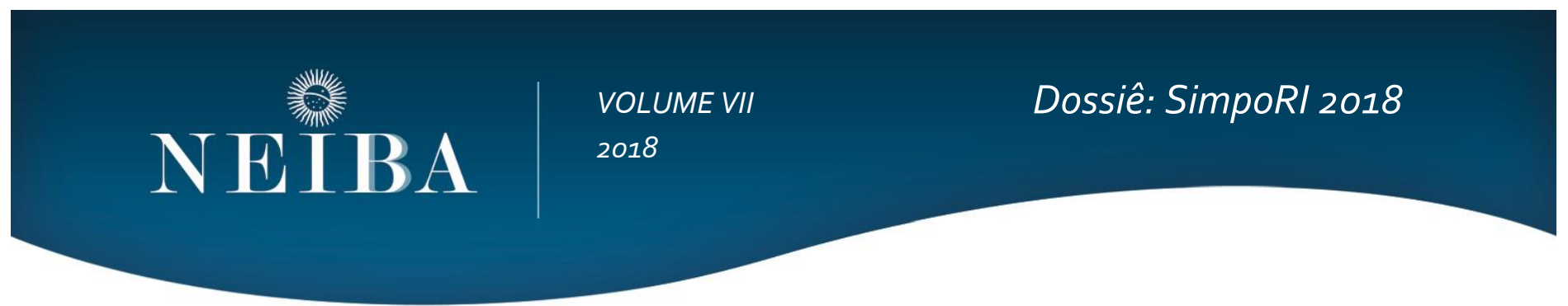

"sugestões de retaliação", que foram postas na imprensa e não pelos senadores ${ }^{10}$.

Será possível perceber, na sequência, como foi montada a análise do Globo, para que, ao final, entenda-se que há uma comunicação política entre a mídia impressa e os agentes formuladores de política externa.

\section{Análise do GLOBO}

Primeiramente, gostaria de salientar que escolhi as seguintes páginas do GLOBO, pois essas apresentaram o maior número de menções ao caso: Primeira Página; Segunda Página; Opinião; Mundo; País; Economia. Além disso, há uma importância na primeira página do jornal, porque "pode informar sobre seus objetivos e sobre a maneira como cada diário se posiciona política, cultural e socialmente" e, também, "reflete as escolhas feitas pelos editores" (MEDEIROS; RAMALHO; MASSARANI, 2010). Esse fato foi constatado nesta pesquisa, uma vez que as primeiras páginas eram indicativas de toda uma cobertura nas páginas subsequentes. A Segunda página era utilizada como se fosse um resumo das principais notícias do jornal, além de demonstrar pesquisas internas acerca de quais matérias chamaram mais a atenção do leitor de uma edição para a outra. A página de Opinião é especialmente importante, porque ela não só é espaço para outras opiniões - o que denotaria uma certa pluralidade -, mas também é espaço para a opinião do jornal. As demais páginas (Mundo, País e Economia) foram escolhidas por serem locus de debates internacionais e que envolvem economia.

A metodologia empregada foi a metodologia de análise devalência ${ }^{11}$ e o mês escolhido foi maio, pois é mês

\footnotetext{
9 Página 25 para as duas aspas.

10 Outra vez em que Celso Amorim se dedica diretamente à imprensa: "se nós devíamos ter respondido à expressão citada em jornal de chantagem, sinceramente, Senador, eu não acho... Aí é uma questão também de percepção" (BRASIL, 2006, grifo meu).
}

em que há um salto de $153 \%$ nas menções à Bolívia no jornal $\mathrm{GLOBO}^{12}$. Nesse sentido, a intenção foi a de qualificar essas menções que tiveram destino o executivo federal, representado por Lula Presidente - não foquei em Lula Candidato -, por Celso Amorim (Ministro das Relações Exteriores) e por Marco Aurélio Garcia (Assessor Internacional da Presidência). Para isso, o método de valência visa a analisar quais notícias são positivas (+1), neutras (0) ou negativas (-1) à imagem do executivo federal e, com isso, far-se-á um gráfico para demonstrar como foi a cobertura sobre esse aspecto, durante o tempo escolhido. A intenção não é, portanto, a de demonstrar intencionalidade ou orientação da instituição do jornal GLOBO, mas, sim, a de analisar o "espaço ocupado [e] a análise quantitativa da cobertura", o que permite "avaliar a valência, ou seja, a orientação positiva ou negativa da cobertura" (ALDÉ, MENDES; FIGUEIREDO, 2007, p.155)

Durante a pesquisa, foi perceptível tal aumento nas menções à Bolívia, em maio de 2006, como demonstra o Gráfico 01. O assunto foi importante durante o mês, perdeu importância durante a Copa do Mundo, voltou a ter importância com a aproximação das eleições de 2006, mas, depois, voltou a ter menções discretas ao final do ano. Com relação à quantidade de menções, maio teve 185 menções à Bolívia contra 83 em abril e contra 57 em junho. Cabe mencionar que pode haver duas ou mais menções na mesma notícia e que a minha análise focou nas páginas que trataram do acontecimento e que se posicionaram com relação às

11 Tal metodologia vem sendo desenvolvida pelo DOXA-IESP e pelo Manchetômetro (disponível em: < http://www.manchetometro.com.br>). Para um debate acadêmico, cf.: Feres Junior (2016).

12 Aldé, Mendes e Figueiredo (2007, p.162) corroboram, ao estudar outros jornais (O Estado de São Paulo e a Folha de São Paulo), juntamente com o GLOBO, quando percebem que "[o] grande pico de Lula Presidente entre 26 de abril e 9 de maio, por exemplo, ocorre em todos os jornais, e corresponde principalmente à crise da Bolivia, com leitura negativa nos jornais estudados" 


\section{NEIBA}

atitudes do executivo federal; não é, portanto, dissociativa o número de páginas com o número de menções ${ }^{13}$.

\section{Gráfico 01}

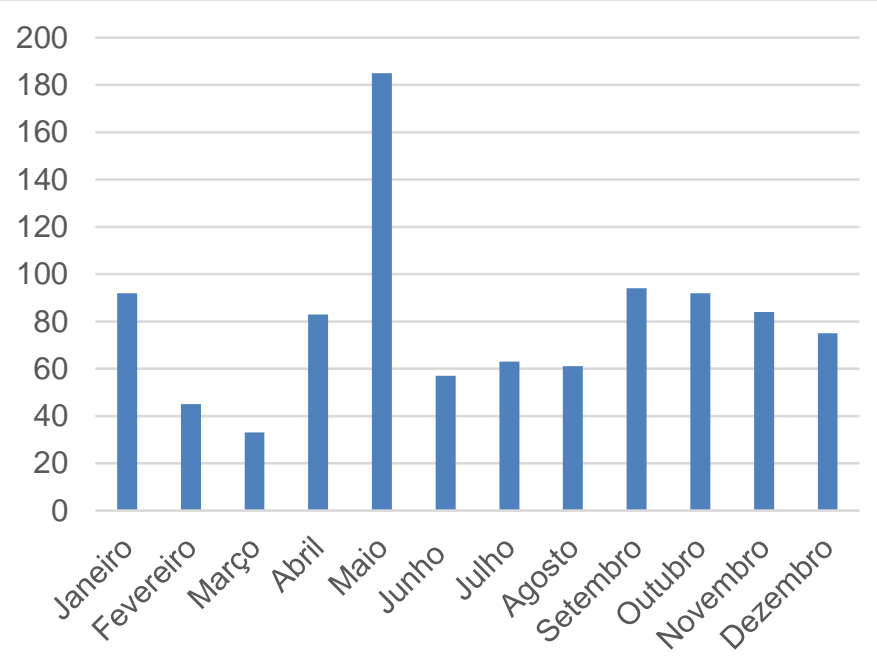

- Menções à Bolívia em 2006

Fonte: o autor

A valência do mês de maio pode ser percebida no Gráfico 02. É importante salientar que o somatório das notícias $^{14}$ ficou em -89 , que não houve qualquer menção positiva ao Lula Presidente nesse mês e que as neutras foram 22. Para que se possa ter um entendimento mais qualificado dessas notícias, discorrerei algumas dessas menções do jornal com o intuito de demonstrar que houve, certamente, falta de pluralidade interna, aliada a uma narrativa que relembra à espiral do silêncio ${ }^{15}$ (NOËLLE-NEUMANN, 1995).

\footnotetext{
13 Há algumas menções na parte de "Carta dos Leitores" e, embora haja uma certa controvérsia com relação a esse uso, preferi não as considerar como parte das notícias do jornal.

${ }^{14}$ Considerei tanto as que haviam caráter noticiosa quanto as que pareciam ser de opinião, mesmo estando fora da página de Opinião.

15 Simplificando um pouco o argumento, pois não é o foco do artigo, reproduzo Hohlfeldt (2009, p. 41): "para Elisabeth Noëlle-Neumann, o ponto central de toda a sua hipótese é a capacidade de que ela reconhece nas
}

Gráfico 02

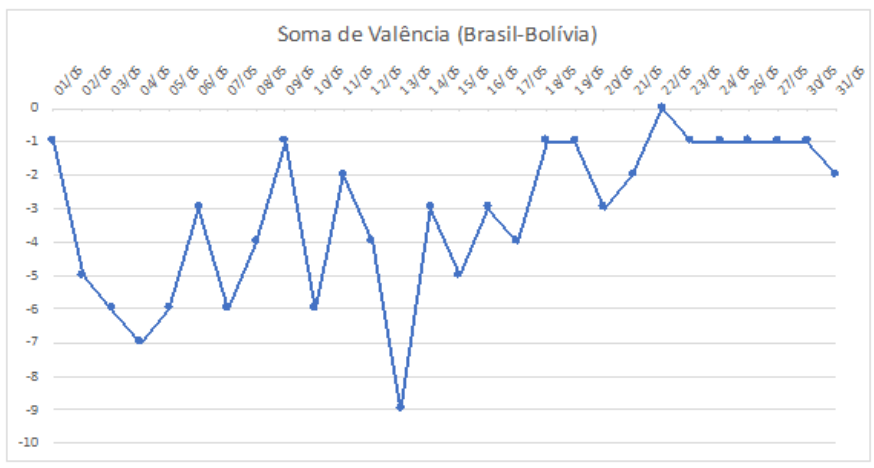

Fonte: o autor

A geolocalização de onde o debate ocorreu é representada na Tabela 01 . Nota-se que o debate ocorre mais nas páginas de Economia ${ }^{16}$ e nas de Opinião ${ }^{17}$. Nas páginas de Economia, houve 10 publicações neutras contra 42 negativas e um forte enfoque no fato de que a Bolívia é um país pobre, com argumentos econômicos, e que, por isso, o Brasil não deveria ceder às "pressões" bolivianas. Para as páginas de Opinião, houve 2 publicações neutras contra 22 negativas e eu gostaria de transcrever algumas para elucidar

pessoas de perceberem o que por ela é denominado de clima de opinião, independentemente do que essas pessoas sintam. Assim, ao perceberemou imaginarem - que a maioria das pessoas pensa diferentemente delas, essas pessoas acabam, num primeiro momento, por se calarem e, posteriormente, a adaptarem, ainda que muitas vezes apenas verbalmente, suas opiniões às dos que elas imaginam ser a maioria. Em consequência, aquela opinião que, talvez de início, não fosse efetivamente a maioria, acaba por tornar-se a opinião majoritária, na medida em que se expressa num crescente movimento de verbalização, angariando prestígio e alcançando a adesão dos indecisos".

16 As páginas de economia, nos jornais brasileiros, têm peso hegemônico desde a década de 70, segundo Donadone (2000). Segundo o mesmo autor (ibidem, p.3): "O estudo realizado por Quintão, sobre o crescimento do noticiário econômico nas primeiras páginas dos jornais brasileiros, constatava que as manchetes de economia passavam, no jornal 'O Estado de São Paulo', de 1,4\% em 1969 para $21,3 \%$ em 1978. No caso do 'Jornal do Brasil', o aumento era de 0,3\% em 1967 para chegar a 27,4\% em 1979 ".

17 A página de Opinião é o loci em que os editores se expressam de maneira mais livre e direta com o leitor. Além disso, "os artigos de opinião têm uma relação estreita com a agenda de media, funcionando como um espaço de comentário da [atualidade]" (FIGUEIRAS, 2007, p. 2094) 


\section{NEIBA}

os "pseudo-debates estruturados em pseudo-polêmicas"18 (FIGUEIRAS, 2007, p. 2105)

\begin{tabular}{c|c}
\hline \multicolumn{1}{c|}{ Páginas } & Contagem de Valência (Brasil-Bolívia) \\
\hline Economia & 52 \\
\hline O Mundo & 7 \\
\hline Opinião & 24 \\
\hline País & 3 \\
\hline Primeira Página & 15 \\
\hline Segunda Página & 10 \\
\hline Total Geral & $\mathbf{1 1 1}$ \\
\hline
\end{tabular}

Entre as páginas de Opinião, o jornal Globo publicou 9 editoriais, todos negativos, para explicitar a sua posição de facto. Percebeu-se que, as notícias das demais páginas seguiam, na maior parte das vezes, os mesmos dizeres das de Opinião, especialmente às que se dedicaram à "Nossa Opinião" - quando é a posição clara do jornal. Na Tabela 02, eu resumi os editoriais para se ter um panorama geral de como o Globo percebeu a nacionalização dos hidrocarbonetos e, como foi demonstrado anteriormente, que os agentes políticos e os formuladores de política externa empreenderam uma comunicação política entre o jornal e eles.

Tabela 02
DIA

\section{Conteúdo resumido}

7

10
"A diplomacia brasileira se torna tributária da outra - ou das outras" A diplomacia brasileira de Lula é "construída com fé fundamentalista
${ }^{18}$ O termo pseudo é empregado, para fins deste artigo e baseado no meu entendimento, a partir de uma finalidade criativa dos jornais em conceber debates envolta de assuntos que são tratados como de interesse da sociedade. Dessa forma, gera-se um ambiente midiático em que os veículos de imprensa se passam por porta-vozes dos interesses comuns e os debatem com argumentos supostamente neutros.

\begin{tabular}{|c|c|}
\hline & $\begin{array}{l}\text { em torno do frágil princípio da } \\
\text { solidariedade entre irmãos latino- } \\
\text { americanos" }\end{array}$ \\
\hline 12 & "Ruína diplomática"19 \\
\hline 13 & $\begin{array}{l}\text { "Diplomacia ideológica não infunde } \\
\text { respeito ao país" }\end{array}$ \\
\hline 14 & $\begin{array}{l}\text { Há possibilidades de cisão na } \\
\text { América do Sul e isso se deve a } \\
\text { posturas ideológicas na diplomacia } \\
\text { da região }\end{array}$ \\
\hline 17 & $\begin{array}{l}\text { Brasília deve agir com o vigor para } \\
\text { proteger os interesses da estatal } \\
\text { (Petrobras) }\end{array}$ \\
\hline
\end{tabular}

\begin{tabular}{l|l} 
& Evo Moráles e Hugo Chávez \\
& ameaçam "levar a América Latina de \\
volta a antigos atoleiros doutrinários \\
e ideológicos"
\end{tabular}

Por conta da "visão ideológica de

24

Lula", Brasil vai continuar a comprar gás da Bolívia, porque este é um país pobre

\section{Delírio ideológico de Lula}

Fonte: Globo (2006) nos dias indicados

O editorial do dia 12 merece ser reproduzido aqui, pois não houve sequer espaço para alguma argumentação ou opinião contrária na página. Após rotular a diplomacia da época de "ruína diplomática" e de mencionar a importância do "militante petista Marco Aurélio Garcia", o jornal segue:

${ }^{19}$ Reproduzirei esse ipsis litteris, uma vez que se foi dedicado todo um editorial para o assunto. 


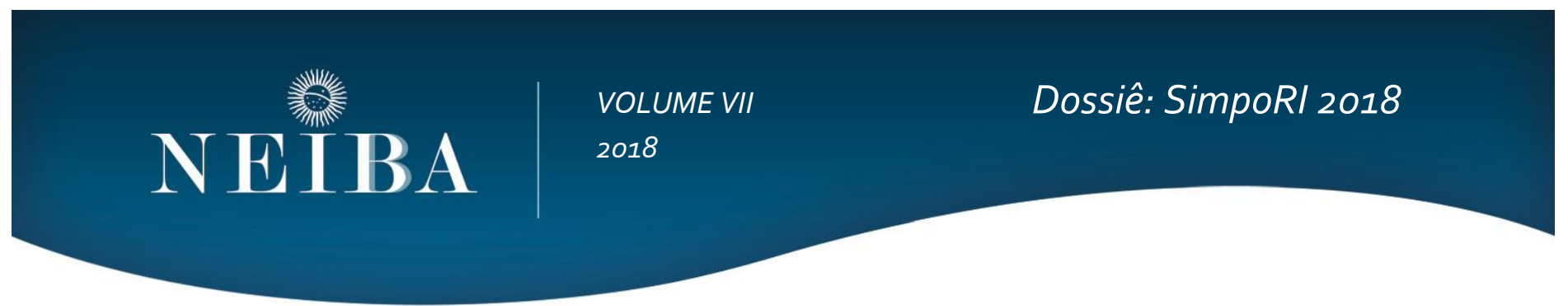

"[E]ntre os escombros da diplomacia de Lula para a região, emerge como líder de parte da América Latina o caudilho venezuelano Hugo Chávez, mais interessado, junto com Fidel Castro, em montar uma cabeça-de-ponte contra os Estados Unidos do que em ajudar a promover o efetivo desenvolvimento integrado da região; Chávez mistura como ninguém diplomacia com ideologia. O governo Lula rompendo com as boas práticas históricas do Itamaraty, fez o mesmo. Daí a derrocada de sua política externa. As lições de prudência, racionalidade e multilateralismo do Barão do Rio Branco foram engavetadas. O Brasil de Lula apostou na visão esclerosada, das décadas de 60 e 70, do conflito Norte-Sul - e perdeu." (GLOBO, 2006)

A partir da análise feita no jornal, considerando a metodologia de análise de valência e o conceito de agenda setting, pode-se afirmar que houve uma opinião majoritária e quase uníssona para com a política externa brasileira, naquela ocasião. Com isso, a pressão foi feita para que o Executivo federal tomasse para si a mesma conduta que o Globo julgou correta. Pôde ser comprovada essa atitude tanto pelo que já foi comentado quanto pelas escolhas de colunistas e dos espaços que seriam para possíveis contraditórios. Segundo o Globo (2006, p. 2), os leitores do jornal já sabiam da possível nacionalização do gás antes mesmo de acontecer e que "[s]e o presidente Lula e a diplomacia brasileira se surpreenderam, foi porque quiseram; o repórter Chico Otávio não foi pego de surpresa".

\section{Aplicando essa análise de comunicação com Política Externa}

A situação envolvendo Brasil e Bolívia, em 2006, pode ser analisada pela ótica de teorias que envolvem Política Externa. Isso já é feito com muito afinco e propriedade pela comunidade acadêmica, mas a minha intenção é a de pode agregar análises de veículos da mídia e poder agregá-los a novas análises. Nesse sentido, explorarei como alguns conceitos de política externa, como o de liderança de Burges (2008), o de potência intermediária de Lima e Hirst (2006) e da dificuldade da expansão brasileira na região de Malamud (2011), têm um ator que influencia o debate, que é a mídia. Não só por questões de espaço, mas também por se tratar de uma demonstração de aplicabilidade prática, não será possível fazer uma análise exaustiva de demais conceitos de política externa e de comunicação.

Partindo da ideia inspirada em Antonio Gramsci de hegemonia consensual, Burges (2008) faz uma comparação com o Brasil e a sua região de influência. Nesse caso, a "hegemonia ganha força a partir do consenso" e não pela sua imposição (BURGES, 2008, p.65). Essa parece ter sido uma das posições possíveis adotadas por Celso Amorim e pelo Executivo federal - a partir da transcrição da audiência pública e da análise do jornal - o que chama atenção é, no entanto, a forma pela qual o jornal parece ter entendido o conceito de liderança para a região. É interessante notar que a noção de hegemonia, para o Globo, é mais afeita às concepções tradicionais de hegemonia, tais como as de Kindleberg, que dá um peso enorme há fatores econômicos, e as de Webb e Krasner, estes têm a hipótese de que a teoria da estabilidade hegemônica é a de que haverá uma abertura à economia internacional e uma estabilidade assim que houver um Estado dominante (BURGES, 2008, p. 67-68). Essas abordagens de hegemonia são, no entanto, divergentes no que se refere à forma pela qual a hegemonia na região poderia ser buscada e isso foi notado tanto por parte do Globo quanto por parte do Executivo federal ${ }^{20}$.

${ }^{20}$ Quando houve menções à política do big stick ser implementada na região, Celso Amorim disse que viu isso na imprensa. O Globo publicou, por sua vez, no dia 17/05 um editorial que cobrava ações com mais vigor para proteger a Petrobrás - constantemente era lembrado que a Petrobrás era uma empresa estatal grande e que representava boa parcela do PIB 


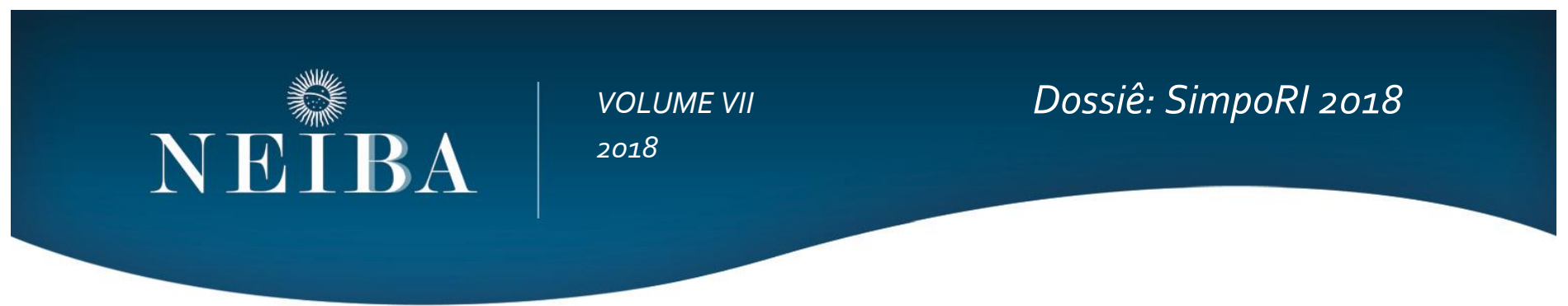

No que se refere à ideia de potência intermediária, Lima e Hirst (2006) elencam algumas possibilidades conceituais nas quais a posição do Executivo e do Globo podem ser encaixadas. Lima e Hirst (2006, p.30) afirmam que, após o início da administração de Lula, "[the] Itamaraty became much more explicit about its desire and its determination to move rapidly towards South American leadership" e que o Itamaraty pressionou para que a América do Sul fosse a prioridade máxima de política externa. Na sequência, Lima e Hirst (2006, p.31-32) entendem que o Brasil tentou promover uma estabilidade política regional ${ }^{21}$, a partir de um spillover effect com a presidência de Lula. Com essa concepção de potência intermediária e essas tentativas de preferência, na região, pode-se depreender duas reflexões. Por um lado, o Globo - durante o mês de maio de 2006 - esteve mais próximo dessa noção de preferência do Itamaraty para a região, ainda que a tenha feito de maneira fortemente negativa, e de seu papel de promotor de estabilidade na região. Por outro lado, os argumentos utilizados por Celso Amorim, em audiência pública, estão mais afeitos à concepção institucionalista-histórica ${ }^{22}$, na qual Lima e Hirst (2006) se baseiam, o que não é muito diferente da maior parte dos discursos diplomáticos que enaltecem as boas relações a partir de um olhar histórico.

O Brasil não tem tido muito suporte de seus vizinhos para políticas internacionais. Esse é um dos argumentos centrais de Malamud (2011) e, de certa maneira, o Brasil tentou empreender uma política externa do regional para o global (PINHEIRO, 2000). Para Malamud (2011, p. 13), "Bolivia has posed one of the toughest challenges to Lula's 'strategy of patience' and to Brazil's policy of foreign

boliviano, fazendo alusões a uma hierarquização econômica entre Brasil e Bolívia, o que daria direito a intervenções com mais vigor (cf. Tabela 02).

${ }^{21}$ Lima e Hirst (2006, p.32) dão um exemplo dessa tentativa de estabilidade regional, antes do caso da nacionalização, na Bolívia. Para as autoras, "[i]n Bolivia, Brazil, together with Argentina, helped mediatein the Lozada-Mesa transitionand acted as a stabilizing force during the 2005 riots which finally led to a new presidential replacementand the call for general election".

22 Para uma ótima explanação sobre diferentes tipos de neoinstitucionalismo, cf. Hall e Taylor (2003). investment and energy integration" e a afinidade de Hugo Chávez com Evo Moráles seria contraproducente à estratégia brasileira de inserção internacional, a partir da região. Com o caso boliviano e com outros que se seguiram na região, Malamud (2011, p.19-20) conclui que a estratégia do Brasil passou para ser mais quieto na região do que um líder e que "its ambitions are increasingly defensive rather than offensive". De fato, o jornal o Globo retratou o caso da Bolívia como uma crise entre os dois países e enquadrou muita a amizade afinidade entre o presidente venezuelano e o presidente boliviano; é, no entanto, importante ressaltar que - Globo discordaria dessa estratégia defensiva e, provavelmente, daria mais respaldo a políticas mais vigoras. Para Celso Amorim e para o Executivo federal, a intenção foi a de não fazer com que esse desentendimento ultrapassasse a esfera diplomática - ainda que se tenha levanto a hipótese da arbitragem internacional - e que não tivesse um spillover effect negativo para o Brasil.

A análise da comunicação política, aliada à análise de política externa, corrobora para uma maior descrição dos acontecimentos que envolvam as duas áreas. A mídia brasileira, especificamente o jornal impresso, tem um papel importante na condução de certas agendas e, em casos como o da audiência pública, a imprensa foi citada como fonte de perguntas e de respostas tanto pelo Legislativo quanto pelo Executivo. É interessante perceber como que o agenda setting dos jornais pôde conduzir, por certos momentos, o debate entre os poderes do Estado.

\section{Conclusão}

Foi perceptível que a imprensa tomou partido e tratou de conduzir uma agenda tanto para o seu público quanto para o governo. As análises de discurso da imprensa e suas comunicações políticas não são novidade, já que diversos autores já a implementam, como Lattman-Weltman (1994), Kucinski (2007), Miguel (1999; 2004) e Lima (2004). Nem as análises de política externa a partir das instituições, como Diniz (2012), Lima e Santos (2001), ou o tempo 


\section{NEIBA}

eleitoral (HIRST; LIMA; PINHEIRO, 2010). A intenção é de seguir uma linha na qual se possa implementar novas técnicas para as análises de política externa para que a mídia entre como um ator relevante. Para tanto, alguns autores já escreveram sobre isso e vale citá-los: Casarões (2012), Faria (2008) e Salomón e Pinheiro (2013), Valente (2007), Camargo (2012) e Franco $(2009)^{23}$.

Friso que, por não ser uma abordagem tradicional, julgo necessária a criação de novas ferramentas de análise de política externa. Para tanto, é importante salientar que a valência ter sido negativa, com relação à nacionalização dos hidrocarbonetos, fez com que fosse possível ir além das abordagens tanto das Relações Internacionais quanto da Comunicação, ao tentar promover um intercâmbio entre os analistas de política externa e os discursos analisados. Com o efeito, o aprofundamento desses intercâmbios seria interessante, por exemplo, em novas análises sobre o papel do Brasil em crises internacionais e a forma pela qual o país se saiu ${ }^{24}$. Dessa forma, a divisão entre páginas de notícias e de opinião, em jornais impressos, aliada à conceitos teóricometodológicos de Relações Internacionais, é um caminho pelo qual pretendo seguir e ressalto que seria significativo que mais acadêmicos atentem para esse complementariedade.

\footnotetext{
23 Além da mídia, há que se pensar, também, no debate acerca da opinião pública, como salientou Lopes (2013, p. 7), ao chamar a atenção para que se leve "em consideração o peso da opinião pública", já que "temas de política exterior passaram a ser introduzidos na esfera pública".

${ }^{24}$ Baseio-me no artigo de Guimarães e Tavares de Almeida (2017).
} 


\section{NEIBA}

VOLUME VII

Dossiê: SimpoRI 2018

2018

\section{BIBLIOGRAFIA}

ALDÉ, Alessandra; MENDES, Gabriel; FIGUEIREDO, Marcus. Tomando partido: imprensa e eleições presidenciais em 2006. Política \& Sociedade, [s.l.], v. 6, n. 10, p.153-172, abr. 2007. Disponível em: <https://periodicos.ufsc.br/index.php/politica/article/view/1688>. Acesso em: 22 out. 2018

BORBA, Felipe. A influência das campanhas nas eleições presidenciais: o papel da mídia. Civitas - Revista de Ciências Sociais, [s.l.], v. 8, n. 2, p.300-322, 20 jan. 2009. EDIPUCRS. http://dx.doi.org/10.15448/1984-7289.2008.2.4765. Disponível em:

<http://revistaseletronicas.pucrs.br/ojs/index.php/civitas/article/view/4765>. Acesso em: 22 out. 2018.

BRASIL. Ministro das Relações Exteriores (2003-2011: Celso Amorim). Ministério das Relações Exteriores. Transcrição da Audiência Pública com o Ministro Celso Amorim na Comissão de Relações Exteriores e Defesa Nacional do Senado Federal sobre as relações Brasil - Bolívia - Brasília, 9 de maio de 2006. 2006. Disponível em: <http://www.itamaraty.gov.br/pt-BR/discursos-artigos-e-entrevistascategoria/ministro-das-relacoes-exteriores-discursos/7815-exposicao-do-ministro-celso-amorim-em-audiencia-publica-da-comissao-derelacoes-exteriores-e-defesa-nacional-do-senado-federal-sobre-as-relacoes-brasil-bolivia>. Acesso em: 20 out. 2018.

Ministério das Relações Exteriores. Relações Bilaterais: Estado Plurinacional da Bolívia. Disponível em:

$<h t t p: / / w w w . i t a m a r a t y . g o v . b r / i n d e x . p h p ? o p t i o n=c o m \_c o n t e n t \& v i e w=a r t i c l e \& i d=4870 \& / t e m i d=478 \&$ cod_pais=BOL\&tipo=ficha_pais\&l ang $=p t-B R>$. Acesso em: 20 out. 2018.

BURGES, Sean W.. Consensual Hegemony: Theorizing Brazilian Foreign Policy after the Cold War. International Relations, [s.l.], v. 22, n. 1, p.65-84, mar. 2008. SAGE Publications. http://dx.doi.org/10.1177/0047117807087243. Disponível em:

<http://journals.sagepub.com/doi/abs/10.1177/0047117807087243>. Acesso em: 25 out. 2018.

CAMARGO, Alfredo José Cavalcanti Jordão de. Bolívia: A Criação de um Novo País a Ascensão do Poder Político Autóctone das Civilizações pré-Colombianas a Evo Morales. Brasília: Funag, 2006. Disponível em: <http://funag.gov.br/loja/download/332-Bollvia__A_Criacao_de_um_Novo_Pals.pdf>. Acesso em: 05 out. 2018.

CAMARGO, Julia Faria. Mídia e Relações Internacionais: lições da invasão do Iraque em 2003. Curitiba: Juruá, 2012. 152 p.

CASARÕES, Guilherme Stolle Paixão e. A MÍDIA E A POLÍTICA EXTERNA NO BRASIL DE LULA. Austral: Revista Brasileira de Estratégia e Relações Internacionais, Porto Alegre, v. 1, n. 2, p.211-236, 2012. Semestral. Disponível em:

<http://seer.ufrgs.br/index.php/austral/article/viewFile/32661/20524>. Acesso em: 14 out. 2018.

COUTINHO, Marcelo. Democracias Andinas: chegando tarde à festa?. Dados, Rio de Janeiro, v. 49, n. 4, p. 795-832, 2006. Available from <http://www.scielo.br/scielo.php?script=sci_arttext\&pid=So011-52582006000400005\&lng=en\&nrm=iso>. access on 21 Oct. 2018. http://dx.doi.org/10.1590/S0011-52582006000400005. 


\section{NEIBA}

DALLE, Pablo; BONIOLO, Paula; SAUTU, Ruth. Manual de metodología.: Construcción del marco teórico, formulación de los objetivos y elección de la metodología. Buenos Aires: Clacso, Consejo Latinoamericano de Ciencias Sociales, 2005. 173 p. Disponível em: <http://bibliotecavirtual.clacso.org.ar/clacso/formacion-virtual/20100719035021/sautu.p df>. Acesso em: 05 out. 2018.

DINIZ, Simone. O senado federal e a deliberação de atos internacionais no presidencialismo brasileiro. Rev. bras. Ci. Soc., São Paulo, v. 27, n. 80, p. 169-184, Oct. 2012. Available from <http://www.scielo.br/scielo.php?script=sci_arttext\&pid=S010269092012000300010\&lng=en\&nrm=iso >. access on 31 Oct. 2018. http://dx.doi.org/10.1590/S0102-69092012000300010.

DONADONE, Julio Cesar. Imprensa de negócios, dinâmica social e os gurus gerenciais. ENCONTRO DA ASSOCIAÇÃO NACIONAL DE PÓS-GRADUAÇÃO E PESQUISA EM ADMINISTRAÇÃO (EnANPAD), 2000. Disponível em:

$<$ http://www.anpad.org.br/admin/pdf/eneo2000-16.pdf>. Acesso em: 21 out. 2018.

FARIA, Carlos Aurélio Pimenta de. Opinião pública e política externa: insulamento, politização e reforma na produção da política exterior do Brasil. Rev. bras. polít. int., Brasilia, v. 51, n. 2, p. 80-97, Dec. 2008. Available from $<h t t p: / / w w w . s c i e l o . b r / s c i e l o . p h p ? s c r i p t=s c i \_a r t t e x t \& p i d=S 0034-73292008000200006 \& / n g=e n \& n r m=i s 0>$. access on 31 Oct. 2018. http://dx.doi.org/10.1590/S0034-73292008000200006

FERES JUNIOR, João. Análise de valências, debate acadêmico e contenda política. Rev. Bras. Ciênc. Polít., Brasília, n. 20, p. 313-322, Aug. 2016. Available from $<$ http://www.scielo.br/scielo.php?script=sci_arttext\&pid=S0103-33522016000200313\&lng=en\&nrm=iso>. access on 23 Oct. 2018. http://dx.doi.org/10.1590/0103-335220162009.

FIGUEIRAS, Rita. O Comentário Político e a Política do Comentário. Comunicação e Cidadania: Actas do 50 Congresso da Associação Portuguesa de Ciências da Comunicação, Braga, v. 1, n. 1, p.2093-2106, set. 2007. Disponível em: <http://revistacomsoc.pt/index.php/5sopcom/article/viewFile/185/181>. Acesso em: 22 out. 2018.

FRANCO, Geisa Cunha. Opinião Pública e Política Externa na Abertura Democrática (1979-1985). Curitiba: Juruá, 2009. 248 p.

FRANÇA, Carlos Alberto Franco. Integração Elétrica Brasil-Bolívia: O encontro no rio Madeira. Brasília: Funag, 2015. 336 p. Disponível em: <http://funag.gov.br/loja/download/1122_integracao_eletrica_brasil_-_bolivia_o_encontro_no_rio_madeira.pdf>. Acesso em: 05 out. 2018.

GERRING, John. Case Study Research: Principles and Practices. [s.l.]: Cambridge University Press, 2007. 279 p.

The Case Study: What it is and What it does. Oxford Handbooks Online, [s.l.], p.1-40, 7 jul. 2011. Oxford University Press. http://dx.doi.org/10.1093/oxfordhb/9780199604456.013.0051. Disponivel em:

$<$ http://www.oxfordhandbooks.com/view/10.1093/oxfordhb/9780199604456.001.0001/oxfordhb-9780199604456-e-051?print=pdf>. Acesso em: 22 out. 2018.

GLOBO. Ruína diplomática. O Globo. Rio de Janeiro, p. 6-6. 12 de maio 2006.

Por dentro Globo: A melhor arma de um repórter. Rio de Janeiro, p. 2. 4 de maio 2006. 


\section{NEIBA}

GUIMARÃES, Feliciano de Sá; ALMEIDA, Maria Hermínia Tavares de. From Middle Powers to Entrepreneurial Powers in World Politics: Brazil's Successes and Failures in International Crises. Latin American Politics And Society, [s.l.], v. 59, n. 04, p.26-46, set. 2017. Cambridge University Press (CUP). http://dx.doi.org/10.1111/laps.12032. Disponível em: $<$ https://www.cambridge.org/core/journals/latin-american-politics-and-society/article/from-middle-powers-to-entrepreneurial-powersin-world-politics-brazils-successes-and-failures-in-international-crises/A41A29EA8FCEoEDB $3 C_{1} D_{11} D_{1} A_{5} C D_{12} 5$ I $_{2}$. Acesso em: 31 out. 2018.

HALL, Peter A.; TAYLOR, Rosemary C. R.. As três versões do neo-institucionalismo. Lua Nova, São Paulo, n. 58, p. 193-223, 2003 . Available from <http://www.scielo.br/scielo.php?script=sci_arttext\&pid=S0102-64452003000100010\&lng=en\&nrm=iso >. access on 27 Oct. 2018. http://dx.doi.org/10.1590/S0102-64452003000100010.

Hirst, Monica; Lima, Maria Regina Soares de \& Pinheiro, Leticia. (2010). A politica externa brasileira em tempos de novos horizontes e desafios. Nueva Sociedad, dezembro, pp. 22-41

HOHLFELDT, Antonio. Espiral do silêncio. Revista Famecos, [s.l.], v. 5, n. 8, p.36-47, 29 jun. 2009. EDIPUCRS. http://dx.doi.org/10.15448/1980-3729.1998.8.5466. Disponivel em:

<http://revistaseletronicas.pucrs.br/ojs/index.php/revistafamecos/article/view/5466/o>. Acesso em: 21 out. 2018.

KUCINSKI, Bernardo. 2007. O antilulismo na campanha de 2006 e suas raízes. In: LIMA, V. A. (org.). A mídia nas eleições de 2006. São Paulo: Fundação Perseu Abramo. 266p.

LATTMAN-WELTMAN, Fernando. 1994. A imprensa faz e desfaz um Presidente: o papel da imprensana ascensão e queda do "fenômeno" Collor. Rio de Janeiro: Nova Fronteira. 166p.

LIMA, Maria Regina Soares de;HIRST, Mônica. "Brazil as an Intermediate State and Regional Power: Action, Choice and Responsibilities." International Affairs (Royal Institute of International Affairs 1944-), vol. 82, no. 1, 2006, pp. 21-40. JSTOR. Disponível em:<www.jstor.org/stable/3569128>. Acesso em 25 out. 2018

LIMA, Maria Regina Soares de; SANTOS, Fabiano. O congresso e a política de comércio exterior. Lua Nova, São Paulo, n. 52, p. 121149, 2001. Available from <http://www.scielo.br/scielo.php?script=sci_arttext\&pid=S0102 $-64452001000100006 \& l n g=e n \& n r m=i s 0>$. access on 31 Oct. 2018. http://dx.doi.org/10.1590/S0102-64452001000100006.

LIMA, Venício Artur de. Mídia: Teoria e Política. Belo Horizonte: Fundação Perseu Abramo, 2004. 368 p.

LOPES, Dawisson Belém. Política externa e democracia no Brasil. São Paulo: Unesp, 2013. 336 p.

MALAMUD, Andrés. A Leader Without Followers? The Growing Divergence Between the Regional and Global Performance of Brazilian Foreign Policy. Latin American Politics And Society, [s. l.], v. 53, n. 03, p.1-24, 2011. Cambridge University Press (CUP). http://dx.doi.org/10.1111/j.1548-2456.2011.00123.x. Disponível em: <https://onlinelibrary.wiley.com/doi/abs/10.1111/j.15482456.2011.00123.x>. Acesso em: 25 out. 2018. 


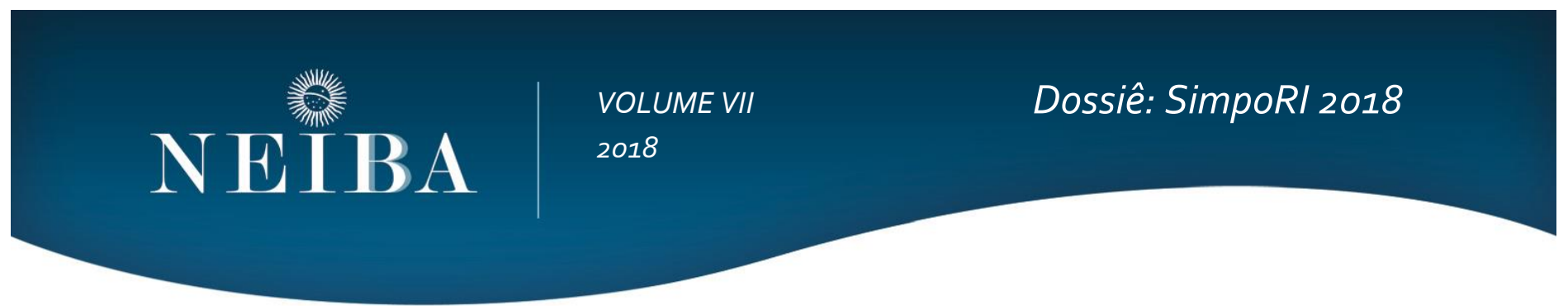

MEDEIROS, Flavia Natércia da Silva; RAMALHO, Marina; MASSARANI, Luisa. A ciência na primeira página: análise das capas de três jornais brasileiros. História, Ciências, Saúde-Manguinhos, Rio de Janeiro, v.17, n.2, abr.-jun. 2010, p.439-454. Disponível em: <https://www.arca.fiocruz.br/bitstream/icict/23929/2/pdf\%2013.pdf>. Acesso em: 20 out. 2018.

MIGUEL, Luis Felipe. Mídia e eleições: a campanha de 1998 na Rede Globo. Dados, Rio de Janeiro, v. 42, n. 2, p. oo, 1999. Available from <http://www.scielo.br/scielo.php?script=sci_arttext\&pid=So011-52581999000200002\&lng=en\&nrm=iso>. access on 31 out. 2018. http://dx.doi.org/10.1590/So011-52581999000200002.

2004. A descoberta da política: a campanhade 2002 na Rede Globo. In: RUBIM, A. A. C. (org.). Eleições presidenciais de 2002 no Brasil: ensaios sobre mídia, cultura e política. São Paulo: Fundação Perseu Abramo.

. A mídia e o declínio da confiança na política. Sociologias, Porto Alegre, n. 19, p. 250-273, jun. 2008.

Disponível em <http://www.scielo.br/scielo.php?script=sci_arttext\&pid=S1517-45222008000100011\&lng=pt\&nrm=iso >. acessos em 31 out. 2018. http://dx.doi.org/10.1590/S1517-45222008000100011.

NITOIU, Cristian. The EU Foreign Policy Analysis: Democratic Legitimacy, Media, and Climate Change. New York: Palgrave Macmillan, 2015. $249 p$

NOËLLE- NEUMANN, Elisabeth.La espiral del silencio. Opinión pública: nuestra piel social, Paidós. Barcelona, 1995.

PERREAULT, Thomas. From the Guerra Del Agua to the Guerra Del Gas: Resource Governance, Neoliberalism and Popular Protest in Bolivia. Antipode, [s.l.], v. 38, n. 1, p.150-172, jan. 2006. Wiley. http://dx.doi.org/10.1111/j.0066-4812.2006.00569.x. Disponível em: <https://onlinelibrary.wiley.com/doi/pdf/10.1111/j.0066-4812.2006.00569.x>. Acesso em: 05 out. 2018.

PINHEIRO, Letícia. Traídos pelo desejo: Um ensaio sobre a teoria e a prática da política externa brasileira contemporânea. Contexto Internacional, Rio de Janeiro, v. 22, n. 2, p.305-335, jun./dez. 2000. Semestral. Disponível em: <http://contextointernacional.iri.pucrio.br/media/Pinheiro_vol22n2.pdfs. Acesso em: 27 out. 2018.

PINHEIRO, Letícia; MILANI, Carlos R. S. (Org.). Política Externa Brasileira: as práticas da política e a política das práticas. Rio de Janeiro: Fgv, 2012. 352 p.

RIGUEIRA, Paulo. Relações internacionais como disciplina. Relações Internacionais, [s.l.], v. 36, n. 3, p.23-46, dez. 2012. Teoria das Relações Internacionais. Disponível em: <http://www.scielo.mec.pt/pdf/ri/n36/n36ao3.pdf>. Acesso em: 21 out. 2018.

SALOMON, Mónica; PINHEIRO, Letícia. Análise de Política Externa e Política Externa Brasileira: trajetória, desafios e possibilidades de um campo de estudos. Rev. bras. polít. int., Brasília, v. 56, n. 1, p. 40-59, 2013. Available from

<http://www.scielo.br/scielo.php?script=sci_arttext\&pid=S0034-73292013000100003\&lng=en\&nrm=iso>. access on 24 out. 2018. http://dx.doi.org/10.1590/S0034-73292013000100003.

VALENTE, Leonardo. Política Externa na era da informação: O novo jogo do poder, as novas diplomacias e a mídia como instrumento de Estado nas Relações Internacionais. Rio de Janeiro: Revan, 2007. 192 p. 